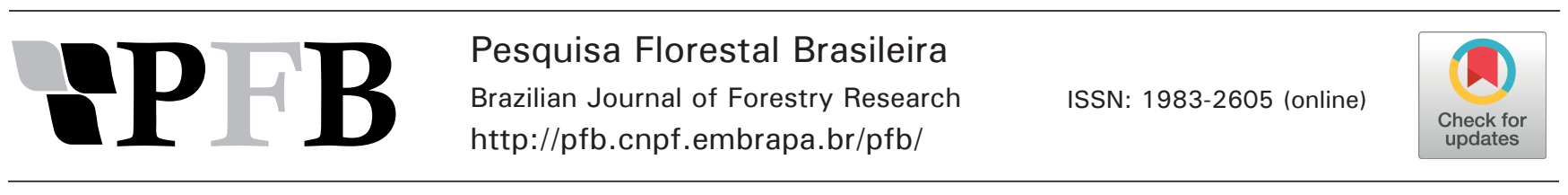

\title{
Torrefação de cavacos de eucalipto para fins energéticos
}

\author{
Matheus Perdigão de Castro Freitas Pereira'*, Emylle Veloso Santos Costa², Bárbara Luísa Corradi Pereira ${ }^{3}$, \\ Ana Márcia Macedo Ladeira Carvalho ${ }^{1}$, Angélica de Cássia Oliveira Carneiro ${ }^{1}$, Aylson Costa Oliveira ${ }^{3}$ \\ 'Universidade Federal de Viçosa, Av. Peter Henry Rolfs, s/n, CEP 36570-900, Viçosa, MG, Brasil \\ Universidade Federal de Lavras, Av. Doutor Sylvio Menicucci, 1001, CEP 37200-000, Lavras, MG, Brasil \\ 'Universidade Federal de Mato Grosso, Av. Fernando Corrêa da Costa, 2367, CEP 78060-900 , Cuiabá, MT, Brasil
}

"Autor correspondente:

matheusperdigao.florestal@gmail.com

Termos para indexação:

Biomassa

Tratamento térmico

Cavacos

Index terms:

Biomass

Thermal treatment

Wood chips

Histórico do artigo:

Recebido em 25/10/2015

Aprovado em 09/09/2016

Publicado em 30/09/2016

doi: $10.4336 / 2016 . p f b .36 .87 .1093$

\begin{abstract}
Resumo - A torrefação, também conhecida como pré-carbonização, é um tratamento térmico, em baixas temperaturas $\left(200^{\circ} \mathrm{C}\right.$ a $\left.300{ }^{\circ} \mathrm{C}\right)$, aplicado a um material lignocelulósico com o objetivo de melhorar suas propriedades energéticas. Desenvolveuse este estudo visando avaliar o efeito da temperatura de torrefação nas propriedades de cavacos de eucalipto. Utilizando uma mufla, os cavacos de eucalipto foram submetidos a quatro tratamentos térmicos com temperaturas de $150^{\circ} \mathrm{C}, 200^{\circ} \mathrm{C}, 250{ }^{\circ} \mathrm{C}$ e $300^{\circ} \mathrm{C}$, por dez min. Foram realizadas análises físicas e químicas dos cavacos torrificados e in natura. Os resultados foram submetidos à análise de variância e quando estabelecidas diferenças significativas, aplicou-se o teste Tukey, a 95\% de significância. Com o aumento da temperatura de torrefação, observou-se maior concentração de lignina e de carbono fixo, menor umidade de equilíbrio higroscópico, maior poder calorífico superior, menor teor de materiais voláteis e de rendimento gravimétrico. Recomenda-se a torrefação a $250{ }^{\circ} \mathrm{C}$, visto que os cavacos torrificados nesta condição apresentaram melhor desempenho, com densidade energética de $4.004 \mathrm{MJ} \mathrm{m}^{-3}$.
\end{abstract}

\section{Torrefaction of eucalyptus wood chips for energy purposes}

\begin{abstract}
Torrefaction also known as pre-carbonization is heat treatment at low temperatures $\left(200{ }^{\circ} \mathrm{C}\right.$ to $\left.300{ }^{\circ} \mathrm{C}\right)$, applied to lignocellulosic materials with the aim of improving their energetic properties. We developed this study to evaluate the effect of torrefaction temperature on properties of eucalyptus chips. Using a furnace, the eucalyptus chips underwent four heat treatments at temperatures of $150{ }^{\circ} \mathrm{C}, 200{ }^{\circ} \mathrm{C}, 250$ ${ }^{\circ} \mathrm{C}$ and $300{ }^{\circ} \mathrm{C}$, for ten min. Physical and chemical analyzes of torrefied and in natura chips were carried out. The results were submitted to analysis of variance and when established significant differences, applied Tukey test at 95\% significance. Increasing roasting temperature showed higher lignin content and fixed carbon, less equilibrium moisture content, higher calorific upper, lower content of volatiles and lower mass yield. It is recommended roasting at $250{ }^{\circ} \mathrm{C}$ temperature, since chips torrefied under this condition presented better results, with energy density of 4,004 $\mathrm{MJ} \mathrm{m}^{-3}$.
\end{abstract}

\section{Introdução}

A madeira é uma fonte importante de energia, tendo gerado no Brasil em 2014 aproximadamente 64,3 GJ, o equivalente a $67 \%$ do consumo de energia do setor brasileiro de florestas plantadas (Indústria Brasileira de Árvores, 2015). Para a produção de energia advinda de madeira na forma de calor, é comum fazer uso do carvão vegetal, subprodutos industriais do setor de celulose (licor preto) ou da queima direta (tora, serragem ou cavacos).

Os cavacos de madeira, também conhecidos como wood chips, são pequenos pedaços de madeira que apresentam melhores características para utilização energética em relação à madeira em tora, como maior área superficial e maior reatividade (Costa et al., 2010), 
acarretando em maior velocidade de queima. Assim, os cavacos têm sido utilizados como insumo para a geração de energia térmica em fornos e caldeiras dos setores de cerâmicas, laticínios, frigoríficos, indústrias esmagadoras de grãos, armazéns, entre outros.

Entretanto, a madeira possui algumas características que diminuem sua eficiência como combustível, das quais podemos citar o alto teor de umidade, baixa densidade, baixo poder calorífico, baixo teor de carbono fixo, além de ser material heterogêneo e higroscópico (Brand et al., 2013; Nones, et al., 2014; Zanuncio et al., 2015). Diante disso, é necessário reduzir a heterogeneidade desse combustível, a fim de padronizar e aumentar sua qualidade para uso energético.

O desafio, então, é utilizar técnicas e tratamentos capazes de tornar a madeira um combustível mais eficiente e competitivo. Uma alternativa seria a torrefação, um tratamento térmico em temperaturas controladas $\left(200{ }^{\circ} \mathrm{C}\right.$ a $\left.300{ }^{\circ} \mathrm{C}\right)$ e em baixa oxigenação, capaz de produzir um material com maior densidade energética comparada à biomassa in natura (Shang et al., 2014). As propriedades do material torrificado variam principalmente em função das propriedades iniciais da madeira, bem como da velocidade de aquecimento, do tempo e da temperatura final do processo (Bergman et al., 2005; Rodrigues \& Rousset, 2009).

A temperatura de torrefação auxilia na redução da higroscopicidade do material (Lora et al., 2013) garantindo desempenhos melhores na geração de energia térmica, visto que há baixa absorção de umidade do ambiente, portanto, menor gasto energético para evaporação da umidade. Outra vantagem da torrefação é a menor atratividade da madeira à microorganismos decompositores, o que permite armazenamento do combustível por períodos mais longos, aumentando sua vida útil (Van der Stelt et al., 2011). Os autores justificam ainda que, apesar da torrefação degradar parcialmente a estrutura fibrosa, diminuindo o rendimento gravimétrico e a resistência do material, ela aumenta a densidade energética, porque concentra o conteúdo energético do material, o que o torna um tratamento térmico promissor.

Sendo assim, este trabalho teve por objetivo avaliar o efeito da temperatura de torrefação nas propriedades físicas e químicas em cavacos de Eucalyptus sp., visando sua utilização energética.

\section{Material e métodos}

O experimento foi conduzido no Laboratório de Painéis e Energia da Madeira, pertencente à Universidade Federal de Viçosa, Viçosa, MG.

Foram utilizados cavacos de madeira de Eucalyptus sp. com 5,5 anos de idade, provenientes de plantios comerciais da empresa Suzano Energias Renováveis, localizados no Estado do Maranhão.

Para reduzir a heterogeneidade do material, evitando diferenças iniciais nos tratamentos térmicos, realizou-se sua secagem e peneiramento. Os cavacos foram secos em estufa com circulação de ar a uma temperatura de $103 \pm$ $2{ }^{\circ} \mathrm{C}$ até alcançar massa constante, ou seja, $0 \%$ de umidade na base seca. O material seco foi peneirado, sendo utilizados aqueles que passaram na peneira com abertura de $31,5 \mathrm{~mm}$ e ficaram retidos na peneira com abertura de $16 \mathrm{~mm}$, tendo em média $28,30 \mathrm{~mm}$ de comprimento, $26,8 \mathrm{~mm}$ de largura e $4,81 \mathrm{~mm}$ de espessura. Além disto, foram retirados os cavacos danificados e as impurezas do material.

\section{Torrefação das amostras}

A torrefação foi realizada em uma mufla de marca Linn Elektro Therm, com capacidade de armazenamento de $0,27 \mathrm{~m}^{3}$. Dentro da mufla foi instalado um recipiente de aço inox $\left(0,125 \mathrm{~m}^{3}\right)$, para limitar a entrada de oxigênio.

Utilizaram-se aproximadamente $500 \mathrm{~g}$ de cavacos livres de umidade para cada torrefação, sendo aplicadas as temperaturas de $150{ }^{\circ} \mathrm{C}, 200{ }^{\circ} \mathrm{C}, 250{ }^{\circ} \mathrm{C}$ e $300{ }^{\circ} \mathrm{C}$. Para cada temperatura realizaram-se três repetições.

A taxa de aquecimento da mufla foi de aproximadamente $5,5^{\circ} \mathrm{C} \mathrm{min}{ }^{-1}$, sendo realizada a leitura da temperatura com o auxílio do equipamento Datalog, instalado dentro do recipiente de aço inox.

O tempo de torrefação foi de 10 min, contados após atingir a temperatura final estabelecida. Ao final, o material foi retirado da mufla e resfriado em dessecador. Salienta-se que o tempo de torrefação foi determinado em experimentos preliminares.

\section{Propriedades da biomassa}

Os cavacos de cada tratamento térmico foram pesados antes e depois do tratamento, a fim de se conhecer a perda de massa no processo e determinar o rendimento gravimétrico, que é a massa de material final (torrificado) em relação à massa inicial, dado em porcentagem. 
A densidade a granel foi determinada seguindo as normativas da EN 15103 (Deutsches Institut fur Normung, 2010).

O poder calorífico superior (PCS) do material foi determinado em bomba calorimétrica, seguindo as normativas da NBR 8633 (Associação Brasileira de Normas Técnicas, 1984).

Para a determinação da umidade de equilíbrio higroscópico do material, as amostras foram colocadas em câmara climática a $20^{\circ} \mathrm{C}$ e $65 \%$ de umidade relativa, até atingir massa constante. A umidade foi calculada em base seca.

A obtenção da composição química foi realizada por meio de amostras moídas e peneiradas na granulometria entre 40 e 60 mesh (American Society for Testing and Materials, 1982). Segundo as normativas da TAPPI T204 OM-88 (Technical Association of the Pulp and Paper Industry, 1996), com substituição do benzeno por tolueno, foi determinado o teor de extrativos. $\mathrm{O}$ teor de lignina insolúvel foi determinado pelo método Klason, modificado de acordo com o procedimento proposto por Gomide \& Demuner (1986). Determinou-se a lignina solúvel por espectrometria ultravioleta, conforme Goldschimid (1971). O teor de lignina total foi obtido pela soma dos valores de lignina solúvel e insolúvel. O teor de holocelulose (celulose + hemiceluloses) foi obtido pela diferença entre o somatório dos teores de lignina total e extrativos com o total de $100 \%$.

A análise química imediata do material torrificado e in natura foi obtida por amostras moídas e peneiradas com granulometria entre 40 e 60 mesh. A análise química imediata, que corresponde aos teores de materiais voláteis, cinzas e carbono fixo, em base seca, foi determinada de acordo com a norma NBR 8112 (Associação Brasileira de Normas Técnicas, 1983), substituindo-se o cadinho de platina por cadinho de porcelana e a temperatura de determinação do teor de cinzas de $7500^{\circ} \mathrm{C}$ para $600{ }^{\circ} \mathrm{C}$.

$\mathrm{O}$ poder calorífico útil (PCU) foi estimado pelas fórmulas:

$$
\begin{aligned}
& \mathrm{PCU}=[\mathrm{PCI}(1-\mathrm{u})]-(600 \mathrm{u}) \\
& \mathrm{PCI}=\mathrm{PCS}-[600(9 \mathrm{H} / 100)]
\end{aligned}
$$

Onde: $\mathrm{PCU}=$ poder calorífico útil $\left(\mathrm{kcal} \mathrm{kg}^{-1}\right), \mathrm{PCI}=$ poder calorífico inferior $\left(\mathrm{kcal} \mathrm{kg}^{-1}\right), \mathrm{u}=$ teor de umidade, $\mathrm{PCS}=$ poder calorífico superior $\left(\mathrm{kcal} \mathrm{kg}^{-1}\right), \mathrm{H}=$ teor de hidrogênio (\%).

A densidade energética $\left(\mathrm{MJ} \mathrm{m}^{-3}\right)$ foi obtida pela multiplicação do poder calorífico útil $\left(\mathrm{kcal} \mathrm{kg}^{-1}\right)$ pela densidade a granel $\left(\mathrm{kg} \mathrm{m}^{-3}\right)$. Após, converteu-se o resultado para $\mathrm{MJ} \mathrm{m}^{-3}$, multiplicando o valor por 0,00419 .

A umidade média considerada para as amostras foi obtida nas estimativas da umidade de equilíbrio higroscópico (UEH) para as amostras de cavacos submetidas em cada um dos tratamentos. Os teores de hidrogênio utilizados foram de $6,31 \%, 6,40 \%, 6,30 \%$, $5,80 \%$ e $5,22 \%$, respectivamente, para o tratamento controle e os tratamentos de $150{ }^{\circ} \mathrm{C}, 200{ }^{\circ} \mathrm{C}, 250{ }^{\circ} \mathrm{C}$ e $300{ }^{\circ} \mathrm{C}$.

\section{Delineamento experimental}

$\mathrm{O}$ experimento foi instalado em delineamento inteiramente casualizado, contendo o tratamento controle e mais 4 tratamentos (temperaturas), em três repetições, totalizando 15 unidades amostrais: controle, $150{ }^{\circ} \mathrm{C}, 200{ }^{\circ} \mathrm{C}, 250{ }^{\circ} \mathrm{C}$ e $300{ }^{\circ} \mathrm{C}$.

Os resultados foram submetidos à análise de variância (ANOVA). Quando estabelecidas diferenças significativas entre eles, aplicou-se o teste Tukey, a 95\% de significância, utilizando o software Statistica 8.0 (Statsoft, 2007).

\section{Resultados e discussão}

$\mathrm{Na}$ Tabela 1 são apresentados os rendimentos gravimétricos e os valores médios da composição química dos cavacos torrificados, livres de umidade, em função dos tratamentos térmicos.

Tabela 1. Valores médios do rendimento gravimétrico (RG) e da composição química dos cavacos: holocelulose (HOL),

\begin{tabular}{|c|c|c|c|c|c|}
\hline \multirow{2}{*}{ Análises } & \multicolumn{5}{|c|}{ Tratamentos } \\
\hline & Controle & $150^{\circ} \mathrm{C}$ & $200^{\circ} \mathrm{C}$ & $250^{\circ} \mathrm{C}$ & $300^{\circ} \mathrm{C}$ \\
\hline RG (\%) & - & $\begin{array}{c}99,40 \text { a } \\
0,02 *\end{array}$ & $\begin{array}{c}98,78 \text { a } \\
0,25^{*}\end{array}$ & $\begin{array}{c}88,19 \mathrm{~b} \\
0,35^{*}\end{array}$ & $\begin{array}{c}60,06 \mathrm{c} \\
0,91^{*}\end{array}$ \\
\hline HOL (\%) & $\begin{array}{c}64,63 \text { a } \\
0,84 *\end{array}$ & $\begin{array}{c}65,10 \mathrm{a} \\
1,35^{*}\end{array}$ & $\begin{array}{c}63,79 \text { a } \\
3,50^{*}\end{array}$ & $\begin{array}{c}58,86 \mathrm{a} \\
4,81^{*}\end{array}$ & $\begin{array}{c}28,75 \mathrm{~b} \\
1,96^{*}\end{array}$ \\
\hline LT (\%) & $\begin{array}{c}32,77 \mathrm{~b} \\
1,42^{*}\end{array}$ & $\begin{array}{c}32,45 \mathrm{~b} \\
1,78^{*}\end{array}$ & $\begin{array}{c}33,18 \mathrm{~b} \\
2,32^{*}\end{array}$ & $\begin{array}{c}36,78 \mathrm{~b} \\
1,49^{*}\end{array}$ & $\begin{array}{c}68,14 \mathrm{a} \\
3,71^{*}\end{array}$ \\
\hline SE (\%) & $\begin{array}{l}2,60 \mathrm{~b} \\
2,95^{*}\end{array}$ & $\begin{array}{l}2,44 \mathrm{~b} \\
2,81^{*}\end{array}$ & $\begin{array}{c}3,03 \mathrm{~b} \\
1,40^{*}\end{array}$ & $\begin{array}{l}4,35 \mathrm{a} \\
2,03 *\end{array}$ & $\begin{array}{c}3,10 \mathrm{ab} \\
4,97^{*}\end{array}$ \\
\hline
\end{tabular}
lignina total (LT) e substâncias extratáveis (SE).

Médias seguidas da mesma letra, na linha, não diferem entre si, a 5\% de probabilidade, pelo teste Tukey. *Coeficiente de variação. 
Foi observado que os tratamentos de $250{ }^{\circ} \mathrm{C}$ e $300{ }^{\circ} \mathrm{C}$ apresentaram diferenças significativas em rendimento gravimétrico, quando comparados aos demais tratamentos (Tabela 1). O maior rendimento gravimétrico do tratamento de $250{ }^{\circ} \mathrm{C}$, quando comparado ao de $300^{\circ} \mathrm{C}$, pode estar relacionado à maior degradação da holocelulose no tratamento de $300^{\circ} \mathrm{C}$.

Observa-se que quanto maior a temperatura, maior é a perda de massa, resultando em menor rendimento gravimétrico (Tabela 1). Isto pode ser explicado pela degradação dos constituintes da madeira, principalmente das hemiceluloses, conforme discutido por Araújo et al. (2012). Rodrigues \& Rousset (2009), trabalhando com madeira de Eucalyptus grandis, também observaram diminuição do rendimento gravimétrico com o aumento da temperatura. Em seu trabalho, os autores encontraram valores de $96,39,88,27$ e $80,15 \%$ de rendimento gravimétrico para tratamentos de 220,250 e $280{ }^{\circ} \mathrm{C}$, respectivamente. Quando submetida ao calor, o primeiro componente a ser degradado na madeira é o grupo das hemiceluloses $\left(220-315^{\circ} \mathrm{C}\right)$, seguido pela celulose $\left(315-400{ }^{\circ} \mathrm{C}\right)$ e a lignina $\left(160-900^{\circ} \mathrm{C}\right)$, assim, o menor rendimento gravimétrico quando o material é submetido a altas temperaturas é explicado pela maior possibilidade de degradação dos seus constituintes (Yang et al., 2007; Carneiro et al., 2013; Pereira et al., 2013; Protásio et al., 2014; Zanuncio et al., 2014).

Os tratamentos de torrefação alteraram a concentração dos constituintes químicos dos cavacos de madeira (Tabela 1). Observaram-se diferenças significativas apenas no tratamento de $300{ }^{\circ} \mathrm{C}$ para os teores de holocelulose e lignina total. A maior degradação das holocelulose no tratamento de $300^{\circ} \mathrm{C}$ explica o aumento proporcional do teor de lignina. A mesma explicação pode ser dada para a relação positiva entre a variação da temperatura e o teor de substâncias extratáveis, que aumenta até os $250{ }^{\circ} \mathrm{C}$. Além disto, Zanuncio et al. (2014) explicam que ao ocorrer a degradação das hemiceluloses, existe a possibilidade de formação de produtos solúveis em álcool/tolueno, resultando em maior teor de extrativos totais contabilizados no material.

O tratamento de $300{ }^{\circ} \mathrm{C}$ foi o que apresentou maior teor de lignina (Tabela 1), sendo este parâmetro o mais indicado para o uso energético. Isso porque a lignina apresenta maior poder calorífico quando comparada aos demais componentes estruturais da madeira (Vital, et al. 2013). A lignina é o componente mais estável à decomposição térmica, o que justifica seu maior teor no tratamento de $300{ }^{\circ} \mathrm{C}$ (Carneiro et al., 2013; LópezGonzález et al., 2013).

Na Tabela 2 são apresentados os valores médios da análise química imediata do tratamento controle e dos cavacos torrificados, livres de umidade.

Tabela 2. Análise química imediata dos cavacos: teores de cinzas $(\mathrm{CZ})$, carbono fixo $(\mathrm{CF})$ e materiais voláteis $(\mathrm{MV})$.

\begin{tabular}{cccccc}
\hline & \multicolumn{5}{c}{ Tratamento } \\
\cline { 2 - 6 } Análise & Controle & $\mathbf{1 5 0}{ }^{\circ} \mathbf{C}$ & $\mathbf{2 0 0}{ }^{\circ} \mathbf{C}$ & $\mathbf{2 5 0}{ }^{\circ} \mathbf{C}$ & $\mathbf{3 0 0}{ }^{\circ} \mathbf{C}$ \\
\cline { 2 - 6 } & & & & \\
& & & & \\
CZ (\%) & $0,33 \mathrm{a}$ & $0,32 \mathrm{a}$ & $0,33 \mathrm{a}$ & $0,31 \mathrm{a}$ & $0,39 \mathrm{a}$ \\
& $7,59^{*}$ & $18,70^{*}$ & $17,95^{*}$ & $21,37^{*}$ & $32,57^{*}$ \\
& & & & & \\
CF (\%) & $12,80 \mathrm{a}$ & $14,52 \mathrm{a}$ & $14,33 \mathrm{a}$ & $18,06 \mathrm{~b}$ & $35,22 \mathrm{c}$ \\
& $3,50^{*}$ & $0,77^{*}$ & $1,77^{*}$ & $2,12^{*}$ & $0,34^{*}$ \\
& & & & & \\
MV (\%) & $86,86 \mathrm{a}$ & $85,16 \mathrm{a}$ & $85,34 \mathrm{a}$ & $81,64 \mathrm{~b}$ & $64,40 \mathrm{c}$ \\
& $0,78^{*}$ & $0,06^{*}$ & $0,28^{*}$ & $0,24^{*}$ & $0,28^{*}$ \\
\hline
\end{tabular}

Médias seguidas da mesma letra, na linha, não diferem entre si, a 5\% de probabilidade, pelo teste Tukey. ${ }^{*}$ Coeficiente de variação.

Observa-se que o teor de carbono fixo aumentou com o aumento da temperatura, sendo verificado o inverso para os materiais voláteis (Tabela 2). A mesma relação foi relatada por Silva (2014), que encontrou valores variando de 86,8 a $73,1 \%$ para materiais voláteis e de 13,0 a $26,7 \%$ para carbono fixo em partículas de madeira de eucalipto in natura e torrificada a $260{ }^{\circ} \mathrm{C}$.

Observou-se um incremento de $41 \%$ e $175 \%$ no teor de carbono fixo no material para os tratamentos de 250 e $300{ }^{\circ} \mathrm{C}$, respectivamente, comparados ao tratamento controle. É sabido que o teor de carbono fixo tem relação positiva com o poder calorífico do material (Soares et al., 2014). O aumento dos teores de carbono fixo é devido à degradação das hemiceluloses e celulose, favorecendo a concentração em porcentagem da lignina no material, constituinte este com teores maiores de carbono na composição (Vital et al., 2013).

O teor de cinzas apresentou alto coeficiente de variação devido ao valor numérico baixo, não sendo observadas diferenças significativas entre tratamentos. As cinzas são provenientes dos componentes minerais da madeira e da casca, e são indesejadas no material, pois têm relação inversa com o poder calorífico e podem causar corrosão nos equipamentos. Outros autores, como Pereira et al. (2013), também encontraram valores inferiores a $0,5 \%$ para o teor de cinzas para madeira de eucalipto. 
Na Tabela 3 são apresentados os valores médios da umidade de equilíbrio higroscópico, densidade a granel, poder calorífico superior, poder calorífico útil e densidade energética dos tratamentos.

Tabela 3. Umidade de equilíbrio higroscópico (UEH), densidade a granel (DG), poder calorífico superior (PCS), poder calorífico útil (PCU) e densidade energética (DEN) dos cavacos.

\begin{tabular}{|c|c|c|c|c|c|}
\hline Tratamento & Controle & $150^{\circ} \mathrm{C}$ & $200^{\circ} \mathrm{C}$ & $250^{\circ} \mathrm{C}$ & $300^{\circ} \mathrm{C}$ \\
\hline UEH (\%) & $\begin{array}{c}12,35 \mathrm{a} \\
0,93 *\end{array}$ & $\begin{array}{c}12,19 \mathrm{a} \\
1,28^{*}\end{array}$ & $\begin{array}{c}11,19 \mathrm{~b} \\
1,50^{*}\end{array}$ & $\begin{array}{l}5,99 \mathrm{c} \\
2,23^{*}\end{array}$ & $\begin{array}{c}5,30 \mathrm{~d} \\
1,29^{*}\end{array}$ \\
\hline $\mathrm{DG}\left(\mathrm{kg} \mathrm{m}^{-3}\right)$ & $\begin{array}{l}212 \mathrm{a} \\
1,80^{*}\end{array}$ & $\begin{array}{l}212 \mathrm{a} \\
2,35^{*}\end{array}$ & $\begin{array}{l}216 \mathrm{a} \\
2,66^{*}\end{array}$ & $\begin{array}{l}221 \mathrm{a} \\
0,79^{*}\end{array}$ & $\begin{array}{l}163 \mathrm{~b} \\
2,18^{*}\end{array}$ \\
\hline PCS $\left(\mathrm{MJ} \mathrm{kg}^{-1}\right)$ & $\begin{array}{c}19,49 \mathrm{~b} \\
0,34^{*}\end{array}$ & $\begin{array}{c}19,54 \mathrm{~b} \\
0,56^{*}\end{array}$ & $\begin{array}{c}19,57 \mathrm{~b} \\
0,15^{*}\end{array}$ & $\begin{array}{c}20,96 \text { a } \\
0,66^{*}\end{array}$ & $\begin{array}{c}20,93 \text { a } \\
0,54^{*}\end{array}$ \\
\hline PCI (MJ kg-1) & $\begin{array}{c}18,08 \mathrm{~b} \\
0,37^{*}\end{array}$ & $\begin{array}{c}18,11 \mathrm{~b} \\
0,60^{*}\end{array}$ & $\begin{array}{c}18,16 \mathrm{~b} \\
0,16^{*}\end{array}$ & $\begin{array}{c}19,40 \mathrm{a} \\
0,70^{*}\end{array}$ & $\begin{array}{c}19,76 \mathrm{a} \\
0,57^{*}\end{array}$ \\
\hline PCU $\left(\mathrm{MJ} \mathrm{kg}^{-1}\right)$ & $\begin{array}{c}15,52 \mathrm{~d} \\
0,37^{*}\end{array}$ & $\begin{array}{c}15,58 \mathrm{~d} \\
0,61^{*}\end{array}$ & $\begin{array}{c}15,83 \mathrm{c} \\
0,16^{*}\end{array}$ & $\begin{array}{c}18,07 \mathrm{~b} \\
0,71^{*}\end{array}$ & $\begin{array}{c}18,56 \text { a } \\
0,57^{*}\end{array}$ \\
\hline $\mathrm{DEN}\left(\mathrm{MJ} \mathrm{m}^{-3}\right)$ & $\begin{array}{c}3.298 \mathrm{~b} \\
2,16^{*}\end{array}$ & $\begin{array}{c}3.316 \mathrm{~b} \\
2,19^{*}\end{array}$ & $\begin{array}{c}3.434 \mathrm{~b} \\
2,49^{*}\end{array}$ & $\begin{array}{c}4.004 \mathrm{a} \\
0,64^{*}\end{array}$ & $\begin{array}{c}3.045 \mathrm{c} \\
2,66^{*}\end{array}$ \\
\hline
\end{tabular}

Médias seguidas da mesma letra, na linha, não diferem entre si, a 5\% de probabilidade, pelo teste Tukey. *Coeficiente de variação.

A redução da umidade de equilíbrio higroscópico é um fator positivo quando se pensa em geração de energia. Quanto menor a umidade de equilíbrio do material em determinadas condições no ambiente, menos energia térmica é consumida para evaporação da água contida no material, resultando em maior poder calorífico útil. Assim, havendo maior disponibilidade de energia útil nos cavacos, menor será o consumo de material.

As hemiceluloses, em geral, são os componentes mais hidrofílicos e mais rapidamente degradados na madeira (Yang et al., 2007; Gomes, et al. 2015). Sendo assim, quando submetido a temperaturas maiores que $200{ }^{\circ} \mathrm{C}$ o material fica menos hidrofílico, visto que ocorre proporcionalmente maior concentração de lignina.

Observou-se redução da umidade de equilíbrio higroscópico com o aumento da temperatura, sendo o tratamento de $300^{\circ} \mathrm{C}$ o que apresentou melhor resultado, com redução de mais de $50 \%$ de UEH comparado aos cavacos in natura. Isto pode ser explicado pela redução do teor de holocelulose e aumento do teor de lignina (Tabela 1).
Silva (2014) também observou relação negativa entre a temperatura e a umidade de equilíbrio higroscópico. Em seu experimento, trabalhando com partículas de madeira de E. urophylla, a UEH reduziu de 12,27\% no material in natura para 5,69\% quando submetida à temperatura de torrefação de $260{ }^{\circ} \mathrm{C}$ por $15 \mathrm{~min}$.

A densidade a granel aumentou até $250{ }^{\circ} \mathrm{C}$ e apresentou uma redução no tratamento a $300{ }^{\circ} \mathrm{C}$ (Tabela 3). O aumento da densidade a granel se deve à contração volumétrica dos cavacos associada à pouca perda de massa, como observado pela média de rendimento gravimétrico no tratamento de $250^{\circ} \mathrm{C}$. Isso não aconteceu no tratamento de $300^{\circ} \mathrm{C}$, onde prevaleceu a perda de massa, como comprovado pelo rendimento gravimétrico, frente à contração volumétrica.

A densidade a granel é um importante parâmetro a ser avaliado, pois interfere no espaço ocupado pela biomassa. Sendo assim, quanto maior a densidade a granel, menor o volume ocupado por uma mesma quantidade de massa, portanto, menor o espaço necessário para transportar ou armazenar o material. A densidade a granel também interfere no dimensionamento da câmara para combustão do material.

Observou-se um ganho em poder calorífico superior com o aumento da temperatura de torrefação, sendo significativamente maior nas temperaturas de $250{ }^{\circ} \mathrm{C}$ e $300{ }^{\circ} \mathrm{C}$ (Tabela 3). Este ganho do poder calorífico superior com o aumento da temperatura está associado, dentre outros motivos, ao aumento da concentração de lignina nos cavacos. Segundo Vital et al. (2013), o poder calorífico da lignina é superior (21 a $27 \mathrm{MJ} \mathrm{kg}^{-1}$ ) ao da celulose $\left(17,2\right.$ a $\left.17,5 \mathrm{MJ} \mathrm{kg}^{-1}\right)$ e das hemiceluloses $\left(16,0 \mathrm{MJ} \mathrm{kg}^{-1}\right)$.

Rodrigues \& Rousset (2009), trabalhando com eucalipto, obtiveram aumentos percentuais de poder calorífico de 3,93\%; 9,56\% e $15,74 \%$ para as madeiras tratadas termicamente nas temperaturas de $220^{\circ} \mathrm{C}, 250$ ${ }^{\circ} \mathrm{C}$ e $280{ }^{\circ} \mathrm{C}$, respectivamente. Neste trabalho, observouse um ganho no poder calorífico superior de $6,14 \%$ e $7,35 \%$, nas temperaturas de torrefação de $250{ }^{\circ} \mathrm{C}$ e $300{ }^{\circ} \mathrm{C}$, respectivamente.

Salienta-se que o menor ganho percentual de poder calorífico superior neste trabalho pode ser explicado pelo tempo de torrefação, que foi de $10 \mathrm{~min}$. Espera-se que o material submetido ao maior tempo de torrefação tenha maior degradação das hemiceluloses e da celulose, com consequente acúmulo de lignina, o que explica o maior ganho em poder calorífico no trabalho de Rodrigues \& Rousset (2009), que trabalharam com 60 min. 
Verificou-se também maior concentração de carbono fixo nos cavacos torrificados (Tabela 3), o que contribui positivamente para o aumento do poder calorífico. O ganho máximo em carbono fixo no tratamento de $300{ }^{\circ} \mathrm{C}$ foi equivalente a $22,76 \%$, quando comparado ao controle.

De maneira geral, o aumento da temperatura elevou o poder calorífico útil (Tabela 3), sendo verificada diferença significativa entre tratamentos. Os cavacos tratados a $250{ }^{\circ} \mathrm{C}$ e $300{ }^{\circ} \mathrm{C}$ apresentaram PCU $16,4 \%$ e $19,6 \%$ maior que o controle, respectivamente, explicado pela menor umidade de equilíbrio higroscópico destes tratamentos e pelo aumento do poder calorífico superior.

A densidade energética se refere à quantidade de energia liberada por volume, sendo útil conhecer a densidade a granel e o poder calorífico útil para o melhor entendimento sobre a densidade energética do material. A densidade energética é um importante parâmetro a ser determinado, pois interfere, por exemplo, no volume de biomassa consumida no processo de queima e no tamanho do silo de armazenamento de biomassa de uma máquina, quando se associa a quantidade de energia necessária e as características do material.

A densidade energética dos cavacos sofreu um acréscimo com o aumento da temperatura até o tratamento de $250{ }^{\circ} \mathrm{C}$ (Tabela 3 ). Novamente, os tratamentos de $250^{\circ} \mathrm{C}$ e $300^{\circ} \mathrm{C}$ apresentaram diferenças significativas comparadas ao controle e entre si.

Apesar do poder calorífico útil do tratamento de $300{ }^{\circ} \mathrm{C}$ ter sido maior, a sua densidade a granel foi muito baixa, interferindo negativamente para o valor final de densidade energética. Sendo assim, observou-se que o tratamento de $250{ }^{\circ} \mathrm{C}$ foi o que apresentou maior potencial, obtendo em média um aumento energético de $21,42 \%$ quando comparado ao tratamento controle, explicados pela diminuição da UEH e pelo aumento da densidade a granel e do poder calorífico superior dos cavacos.

\section{Conclusões}

A torrefação melhorou as propriedades dos cavacos de eucalipto para fins energéticos.

De maneira geral, quanto maior a temperatura de torrefação menor o rendimento gravimétrico, os teores de holocelulose, materiais voláteis e a umidade de equilíbrio higroscópico. Em contrapartida, aumentamse os teores de lignina total, substâncias extratáveis, o teor de carbono fixo, o poder calorífico superior e útil.

$\mathrm{O}$ tratamento de $250{ }^{\circ} \mathrm{C}$ apresentou alto rendimento gravimétrico, baixa umidade de equilíbrio higroscópico, alto poder calorífico superior e o útil, além de maior densidade energética, sendo considerado o mais indicado para a torrefação, por seu melhor desempenho.

\section{Referências}

American Society for Testing and Materials. Standard methods of evaluating properties of wood-base fiber and particles materials. Philladelphia, 1982.

Araújo, S. D. O. et al. Propriedades de madeiras termorretificadas de Eucalyptus grandis e SP. Scientia Forestalis, v. 40, n. 95, p. 327-336, 2012.

Associação Brasileira de Normas Técnicas. NBR 8112: carvão vegetal: análise imediata. Rio de Janeiro, 1983.

Associação Brasileira de Normas Técnicas. NBR 8633: carvão vegetal: determinação do poder calorífico. Rio de Janeiro, 1984.

Bergman, P. C. A. et al. Torrefaction for entrained-flow gasification of biomass. Netherlands: Energieonderzoek Centrum Nederland, 2005. $51 \mathrm{p}$.

Brand, M. A. et al. Análise da qualidade da madeira e do carvão vegetal produzido a partir da espécie Miconia cinnamomifolia (De Candolle) Naudin (Jacatirão-açu) na agricultura familiar, em Biguaçu, Santa Catarina. Scientia Forestalis, v. 41, p. 401-410, 2013.

Carneiro, A. C. O. et al. Conversão direta da madeira em calor e energia. In: Santos, F. et al. (Ed.). Bioenergia \& biorrefinaria: cana-de-açúcar \& espécies florestais. Viçosa, MG, 2013. p. 355-378.

Costa, D. R. et al. Consumo específico de energia no processamento de madeira em cavacos de um picador (estudo de caso). Engenharia na agricultura, v. 18 , n. 2, p. 171-177, 2010. DOI: 10.13083/14143984.v18n02a08.

Deutsches Institut fur Normung. DIN EN 15103: solid biofuels: determination of bulk density. Alemanha, 2010.

Goldschimid, O. Ultraviolet spectra. In: Sarkanen, K. V. \& Ludwing, C. H. (Ed.). Lignins. New York: Wiley Interscience, 1971. p. 241266.

Gomes, V. J. et al. Influência do conteúdo de xilanas na branqueabilidade, propriedades higroscópicas, fisico-mecânicas e óptica de polpas branqueadas de eucalipto. Química Nova. v. 38, p. 221-226, 2015. DOI: 10.5935/0100-4042.20140309.

Gomide, J. L. \& Demuner, B. J. Determinação do teor de lignina em material lenhoso: método Klason modificado. O Papel, v. 47, n. 8, p. 36-38, 1986.

Indústria brasileira de árvores. IBÁ. Brasília, DF, 2015. Relatório IBÁ 2015. Disponível em: <http://www.iba.org/images/shared/ iba 2015.pdf>. Acesso em: 3 ago. 2015.

López-González, D. et al. Thermogravimetric-mass spectrometric analysis on combustion of lignocellulosic. Bioresource Technology, v. 143 , p. $562-574$, set. 2013. DOI:10.1016/j.biortech.2013.06.052. 
Lora, E. E. S. et al. Torrefação de madeira. In: Santos, F. et al. (Ed.) Bioenergia \& biorrefinaria: cana-de-açúcar \& espécies florestais. Viçosa, MG, 2013. p. 401-427.

Nones, D. L. et al. Determinação das propriedades energéticas da madeira e do carvão vegetal produzido a partir de Eucalyptus benthamii. Floresta, v. 45, p. 57-64, 2014. DOI: 10.5380/ rf.v45i1.30157.

Pereira, B. L. C. et al. Estudo da degradação térmica da madeira de Eucalyptus através de termogravimetria e calorimetria. Revista Árvore, v. 37, n. 3, p. 567-576, 2013. DOI: 10.1590/S010067622013000300020 .

Protásio, T. P. et al. Clones comerciais de Eucalyptus de diferentes idades para o uso bioenergético da madeira. Scientia Forestalis, v. 42, n. 101, p. 113-127, 2014.

Rodrigues, T. O. \& Rousset, P. L. Effects of torrefaction on energy properties of Eucalyptus grandis Wood. Cerne, v. 15, n. 4, p. 446$452,2009$.

Shang, L. et al. Kinetic model for torrefaction of wood chips in a pilot-scale continuous reactor. Journal of Analytical and Applied Pyrolysis, v. 108, p. 109-116, 2014. DOI: 10.1016/j. jaap.2014.05.010.

Silva, C. M. S. Efeito da temperatura de torrefação nas propriedades energéticas da madeira de eucalipto. 2014. $41 \mathrm{f}$. Monografia (Bacharel em Engenharia Florestal) - Universidade Federal de Viçosa, Viçosa, MG.
Soares, V. et al. Correlações entre as propriedades da madeira e do carvão vegetal de híbridos de eucalipto. Revista Árvore, v. 38, n. 3, p. 543-549, 2014. DOI: 10.1590/S0100-67622014000300017.

Statsoft Inc. Statistica data analysis system version 8.0. Tulsa, 2007.

Technical Association of the Pulp and Paper Industry. TAPPI test methods T 204 om-88: solvent extractives of wood and pulp. Atlanta, 1996. v. 1.

Van der Stelt, M. J. C. et al. Biomass upgrading by torrefaction for the production of biofuels: a review. Biomass and Bioenergy, v. 35, p. 3748-3762, 2011. DOI: 10.1016/j.biombioe.2011.06.023.

Vital, B. R. et al. Qualidade da madeira para fins energéticos. In: Santos, F. et al. (Ed.) Bioenergia \& biorrefinaria: cana-de-açúcar \& espécies florestais. Viçosa, MG, 2013. p. 321-354.

Yang, H. et al. Characteristics of hemicellulose, cellulose and lignin pyrolysis. Fuel, v. 86, n. 12, p. 1781-1788, 2007. DOI: 10.1016/j. fuel. 2006.12.013.

Zanuncio, A. J. V. et al. Propriedades energéticas da madeira e carvão de Corymbia e Eucalyptus em diferentes condições de secagem. Revista Brasileira de Ciências Agrárias: Agrária, v. 10, n. 3, p. 432-436, 2015. DOI: 10.5039/agraria.v10i3a3601.

Zanuncio, A. J. V. et al. Química e colorimetria da madeira de Eucalyptus grandis W. Mill ex Maiden termorretificada. Revista Árvore, v. 38, n. 4, p. 765-770, 2014. DOI: 10.1590/S010067622014000400020 . 
